\title{
A New Daily Dividend-adjusted Index for the Danish Stock Market, 1985-2002: Construction, Statistical Properties, and Return Predictability
}

Klaus Belter, Tom Engsted and Carsten Tanggaard Department of Finance, Aarhus School of Business, Fuglesangs allé 4, DK-8210 Aarhus V. December 2002.

\begin{abstract}
We present a new dividend-adjusted blue chip index for the Danish stock market covering the period 1985-2002. In contrast to other indices on the Danish stock market, the index is calculated on a daily basis. In the first part of the paper a detailed description of the construction of the index is given. In the second part of the paper we analyze the time-series properties of daily, weekly, and monthly returns, and we present evidence on predictability of multi-period returns. We also compare stock returns with the returns on long-term bonds and short-term money market instruments (i.e. the equity risk premium), and we compute the Hansen-Jagannathan bound to infer the properties of the underlying stochastic discount factor generating Danish asset returns.
\end{abstract}

Keywords: Asset market returns, mean-reversion and predictability, Hansen-Jagannathan bound.

JEL Codes: G10, G12

\section{Introduction.}

There is a long tradition in finance for statistical analysis of stock returns. The US stock market, in particular, has been the focus for numerous studies, since good long-term return data at both yearly, monthly, and weekly frequencies exist for this country (e.g., the CRSP data). For many other countries there exist stock index series on a yearly basis that include dividends, but dividend-adjusted series at higher frequencies are scarce. Usually only capital gains are included. Among the exceptions are Frennberg and Hansson (1992) and Dimson and Marsh (2001), who 
construct monthly dividend-adjusted stock return series for Sweden and the UK, respectively. ${ }^{1}$

For Denmark, various attempts have been made to construct stock market indices that include dividends. Lund (1992), Lund and Engsted (1996), and Parum (1999), for example, construct such indices starting in the 1920's. These indices, however, are all on a yearly basis, which precludes analysis of the high-frequency properties of returns. ${ }^{2}$

The purpose of the present paper is two-fold. First, to present a dividend-adjusted blue chip index for the Danish stock market on a daily basis covering the period since June 1985. Second, based on this index, to investigate the statistical properties of Danish stock returns. In addition, we compare Danish stock returns with the returns on Danish long-term bonds and short-term money market instruments. We analyze the mean-, variance-, and autocorrelation properties of returns at various frequencies (daily, weekly, and monthly), and we test for mean-reversion and predictability of returns over horizons from 1 month to 4 years. Finally, we use the Hansen and Jagannathan (1991) methodology to infer the properties of the underlying stochastic discount factor generating the Danish asset market returns. The paper is thought to be a reference point for finance researchers and practitioners interested in the Danish stock market, and the underlying database is available upon request from the authors. ${ }^{3}$

Section 2 gives a detailed description of the construction of the new index. Section 3 contains various statistical analyses of returns. Finally, section 4 concludes the paper.

\section{A Danish stock market index.}

The official blue chip stock index at the Copenhagen Stock Exchange, the KFX, has been calculated on a daily basis since July $3 r d, 1989$. The KFX index is a market value weighted price index. That is, the index is a measure of the price development of the constituent companies, and the applied weighting scheme is market value. Being a price index, the

\footnotetext{
${ }^{1}$ Recently researchers have shown a great interest in documenting cross-country differences in stock market returns, e.g. Campbell (1999), Jorion and Goetzmann (1999), and Dimson et al. (2002). See also the special issue of European Journal of Finance (1999) dealing with security returns in Europe.

${ }^{2}$ Contrary to market microstructure analyses, we think of daily, weekly and monthly sampling as being high-frequent.

${ }^{3}$ Detailed index documentation is also available upon request, including: i) A list of important events such as mergers and de-mergers. ii) Dates of corporate actions and corresponding changes in listed capital. iii) A specification of each index portfolio including the market value of each constituent security. iv) A list of changes in idcodes among index securities.
} 
KFX is not adjusted for cash dividends. Hence, the KFX is systematically downward biased and, therefore, inapplicable to e.g. performance evaluation studies.

We construct two stock indices referred to as the ex-dividend price index and the dividend-adjusted price index, respectively. Both indices cover the period from June 1985 to March 2002. The only difference between the two indices is the re-investment of cash dividends included in the latter index. The index is a measure of the total return to an investor who continuously reinvests cash dividends in the index portfolio, i.e. a measure of a "buy and hold" return. We find that our dividendadjusted index is an accurate and unbiased measure of the performance of an investor who holds a market value weighted portfolio of Danish blue chip securities and reinvests all cash dividends in the constituent securities.

Since our ex-dividend price index aims at mimicking the official KFX index, we have compared our index with the official KFX index. Table 1 shows that the two price indices are highly correlated, especially at the monthly and quarterly frequencies. The discrepancy between the official KFX index and our ex-dividend price index at a daily frequency is primarily the result of differences in the handling and the timing of portfolio updates around corporate actions, c.f. section 2.1.2 below.

\subsection{Index construction.}

The construction of stock market indices is in principle not different from the construction of other price indices, consumer price indices for example. An index is supposed to track the total value of a basket of commodities - in the case of stock market indices a portfolio of stocks with fixed or time-varying weights.

The general principles of index construction are presented in Allen (1975), while Fisher and Weaver (1992) present the general principles for the construction of security price indices. In the following we use the notation from Fisher and Weaver (1992). We start by studying index construction without correction for dividends and other cashflows resulting from corporate actions.

Define $I(t)$ and $I(t-j)$ as the level of a security index at time $t$ and time $t-j$, respectively. Next, define a formula for the chaining of the index levels between different points in time

$$
I(t)=L(t-j, t) I(t-j) .
$$

$L(t-j, t)$ is a link-relative factor. In the actual construction of the index, we set $j$ equal to one as we chain the index between adjacent 
trading days. Now, define $L(t-j, t)$ as

$$
L(t-j, t)=\sum_{i=1}^{N} w_{i}(t)\left[p_{i}(t) / p_{i}(t-j)\right] / \sum_{i=1}^{N} w_{i}(t),
$$

where $p_{i}(t)$ is the share price of the $i t h$ stock, $N$ is the number of stocks in the index portfolio, and $w_{i}(t)$ is a weight. The index weight may be constant or change with security changes. Commonly used choices for index weights are market values, share prices, or equal weights.

Formula (2) shows that the link-relative is the weighted average of wealth-relatives for each stock in the index portfolio. The market value weighted index (MVWI) sets $w_{i}(t)=n_{i}(t-j) p_{i}(t-j)$, where $n_{i}$ is the number of shares of stock $i$. Simple algebra shows that

$$
L(t-j, t)=\sum_{i=1}^{N} n_{i} p_{i}(t) / \sum_{i=1}^{N} n_{i} p_{i}(t-j)
$$

Thus, the MVWI is updated by the wealth relative (or gross return) on the index portfolio.

Table 2 shows the weights for two other weighting schemes: the price weighted and the equally weighted indices. The price weighted index measures the total return for an investor who owns one share in each security from the index portfolio. Thus, despite their names both the value and the price weighted index are estimators of the return on fixednumber-of-shares portfolio strategies. The equal weighted index is the simple average of the gross return on each security. This does not correspond to any easily understood portfolio strategy with a fixed number of shares. This makes the index a somewhat dubious benchmark index. The only merit of the equally-weighted index seems to be the simplicity of it's construction. In addition, the equally weighted index is sensitive to microstructure effects such as bid-ask bounce and non-synchronous trading (see Fisher and Weaver, 1992).

All three special cases of expression (2) are applied in major financial markets. The majority of indices are calculated by the value weighted approach, though. The "S\&P 500", the "NYSE Composite" and the "NASDAQ 100" are value weighted indices. The "Dow Jones Industrial Average" is one example of a price weighted index. Likewise, most theoretical applications are based on the value weighted algorithm since it often offers a satisfactory proxy for the market portfolio. Since we only estimate market value weighted indices in this paper, the focus is now exclusively directed towards the market value weighted algorithm. 


\subsubsection{Correction for cash dividends}

Cash dividends are payments from the company to the equity owners. The market value of a company is reduced as a result of the payment of cash dividend. However, from the perspective of an investor, the reduction in the security price is offset by an increase in the cash position.

Cash dividends are handled by assuming reinvestments into the index portfolio. Recall the formula for chaining market value weighted indices, (3). If $p_{i}(t-j)$ is the with-dividend closing price registered at time $t-j$, and $p_{i}(t)$ is the ex-dividend price registered at time $t$, then (3) must be be adjusted to reflect the reinvestment in the index.

We know of two different ways to increase the link-relative in order to measure the total return. First, one can subtract the dividend, $D_{i}$, from the denominator. Alternatively, one can add the dividend to the numerator. The latter method is the one recommended for empirical research in Campbell et al (1997), p.12. The former method is the one applied by the NOREX family of exchanges to which the Copenhagen Stock Exchange belongs, NOREX (2000). An adjustment of the denominator can be interpreted as a reinvestment of cash dividends to the prices at time $t-j$, i.e., the shares are bought at a price of $p_{i}(t-j)$ less dividends. Contrary, using a numerator adjustment the time of reinvestment is $t$.

The difference between the two adjustment methods can be assessed by considering the case of a single security. Define $\mathrm{p}^{e x}$ as the ex-dividend price, and define $\mathrm{p}^{\text {with }}$ as the with-dividend price. The relationship between $\mathrm{p}^{e x}$ and $\mathrm{p}^{\text {with }}$ is the following

$$
p^{e x}=p^{\text {with }}-D+\epsilon,
$$

where $\epsilon$ is the part of the price change between the ex-dividend date and the with-dividend date which is related to other sources than the dividend payout. If $\epsilon=0$ the numerator and denominator correction methods yield identical results. However, if $\epsilon>0$ the denominator correction yields the highest link-relative. In contrast, the denominator correction returns the smallest link-relative when $\epsilon<0$.

In order to assess the empirical difference between the two correction methods we have estimated the return index using both methods. We find that the difference between the two approaches is very small: it amounts to $0.15 \%$ in total return over the 17 -year period. In conclusion, we proceed by estimating the return index using the denominator adjustment.

\subsubsection{Correction for corporate actions}

The market value of a company can change as a result of changing expectations of future business opportunities among investors. In addition, 
the market value of a company may change if the company succeeds in attracting new capital from its shareholders. Such cases of capital inflow from investors to the company forms a substantial part of what we refer to as corporate actions. However, corporate actions also include cases where no funds are transferred from investors to the company. In both cases it is important to generalize the link relative (3), since from an investor perspective the net gain is zero. In what follows we show how to modify expression (3) to consistently handle both cases of corporate actions.

An example of a corporate action which does not involve a transfer of funds from investors to the company is a standard stock split. A modified version of expression (3) is applied in such cases

$$
L^{*}(t-j, t)=\sum_{i=1}^{N} n_{i}^{*} p_{i}(t) / \sum_{i=1}^{N} n_{i} p_{i}(t-j),
$$

where $n_{i}^{*}$ represents the number of listed shares in the ith company following the stock split. In the case of a stock split of 2 shares for 1 a routine application of the chaining formula (3) reduces the index value by a factor $1 / 2$ stemming alone from the reduction in share price induced by the split. Naturally, the link-relative must take the increased number of shares into account.

We now consider corporate actions which involve a transfer of funds between the company and investors. Such cash flows can be regarded as a sort of negative dividend from an investor perspective. The wealth of investors is left unaffected. However, the share price of the company increases. In expression (6) we generalize expression (3) to such cases,

$$
\begin{gathered}
L^{*}(t-j, t)=\sum_{i=1}^{N} n_{i}^{*} p_{i}(t) /\left(\sum_{i=1}^{N} n_{i} p_{i}(t-j)+e\right), \\
e=\sum_{i=1}^{N} \Delta_{i} p_{i}^{*}(t-j),
\end{gathered}
$$

where $e$ is a correction term defined as $\Delta_{i}$, the number of new stocks issued by the ith company, multiplied by the corresponding issue price, $p_{i}^{*}$. That is, expression (7) represents the cash inflow to the ith company. Expression (6) is a standard expression used by a wide range of index suppliers, e.g. the Copenhagen Stock Exchange.

First, consider a rights issue for existing shareholders at discount price. The market value is increasing following such an issue. However, the cash deposit paid by the investors is the sole source of the increase. Hence, the increase does not represent an increase in investor wealth. 
Next, consider an issue at market prices. The end result is the same as above, namely an increase in the market value of the company. Again, expression (3) would be an upward biased estimator, since the increase in market value is generated by cash deposits to the company from the investors.

We apply an approximation to (6) to estimate the ex-dividend price index and the dividend-adjusted price index. We are unable to apply (6) in its pure form since we do not observe all discount prices of rights issues for existing shareholders. To circumvent these shortcomings the applied algorithm places zero weight on a company until two prices under the new capital structure are observed. That is, the company is prevented from contributing to the updating of the link-relative. Consequently, a difference between the official KFX index and our return index exists, especially for the daily frequency, see Table 1, since our investor holds a different portfolio around these events. The applied correction can be interpreted as a sale on the date of the corporate action and a buy-back when we observe two prices under the new capital structure. In our view the procedure is robust and unbiased.

Another issue is the time of portfolio adjustment. The Copenhagen Stock Exchange adjusts the relative position in each company on the first date of a new index portfolio. The only exception to this rule is with respect to rights issues for existing shareholders at discount prices. On the contrary, we apply immediate updating of the portfolio at the time of the corporate action. One can think of the applied algorithm as one where the investor takes part in the issue, and as a result the relative weights are immediately affected.

\subsubsection{Data and portfolio selection rules}

Data is from the financial database "The Danish Stock Database", which was developed - and is maintained - at the Aarhus School of Business. The database contains data from the Copenhagen Stock Exchange since January 1985. We need 6 months of data for the construction of the index portfolio as of June 1985. Therefore, the first index value is dated June 1985.

We use the following data in the estimation of the indices: Transaction price, turnover, date of the general assembly of equity owners, cash dividend and, finally, the listed capital. The database does not contain complete information on the dates of corporate actions. Consequently, we have used written material from the Copenhagen Stock Exchange to find the exact dates of changes in listed capital.

We have adapted to the criteria for index portfolio selection suggested by the Copenhagen Stock Exchange. Throughout the entire pe- 
riod, market value and liquidity have been the criteria for inclusion of companies into the KFX index portfolios. Hence, the index portfolios for the estimated price indices are identical to the index portfolios used by the Copenhagen Stock Exchange in the calculation of the KFX index in the 1989-2002 period. From 1989 to 1992 the index portfolios consist of 25 constituent securities and the portfolios are revised on a quarterly basis. Contrary, in the 1992-1999 period, 20 securities were selected on a yearly basis. In recent years 20 securities have been selected on a 6 month basis.

To ensure consistency we have applied an analogous portfolio selection criterion in the pre-KFX period from June 1985 to July $3 r d, 1989$. That is, in the 6 month period prior to a revision of the index portfolios, we rank the securities by turnover on a daily basis. Based on these rankings we select the 30 most traded stocks at the Copenhagen Stock Exchange. Finally, from this sub-set of securities we select the 20 most valuable securities from a market value criterion. New index portfolios are implemented at the beginning of June and December throughout the pre-KFX period. Overall, the pre-KFX period adds 9 index portfolios to the official KFX portfolios.

\section{Statistical properties, mean-reversion, and pre- dictability.}

In this section we analyze the time-series properties of our Danish stock index at a daily, weekly, and monthly frequency. Figures 1 to 3 plot the return series at these three frequencies, respectively. (For the most part the sampling frequency in this section will be monthly). ${ }^{4}$ In addition, we investigate the properties of Danish bond returns. We will look at returns measured over horizons from one month to four years, both in nominal and real terms, and in excess of a short-term interest rate. That is, we explicitly investigate risk-premia on stocks and bonds. The data for bond returns and money market interest rates have been supplied by the Danish mutual fund, "Sparinvest". Inflation and real values are obtained using the consumer price index from "Statistics Denmark". Figure 4 plots the monthly return on long-term government bonds and Figure 5 plots the 3 -month interest rate.

Previous analyses of returns in the Danish stock and bond markets have been conducted by Lund (1992), Lund and Engsted (1996), Parum (1999), Engsted et al. (2000), Engsted and Tanggaard (1999, 2001),

\footnotetext{
${ }^{4}$ The weekly returns are measured from Tuesday to Tuesday. If Tuesday is not a business day Wednesday is used instead. If Wednesday is not a business day Monday is used. If neither Monday nor Wednesday are business days, we exclude that week from the analysis. The monthly returns are calculated as middle-of-month.
} 
Engsted (2002), and Dimson et al. (2002). These studies use annual data over more than 70 years. A typical and interesting finding is that the average Danish equity premium is quite low (less than 4\%) but also quite variable (more than 20\% standard deviation). In fact, based on these long-span data, for Denmark there does not seem to be an equity premium puzzle of the kind that Mehra and Prescott (1985) and many others have found for the US (c.f. Engsted et al., 2000; Engsted, 2002).

The first column in Table 3 reports the mean and standard deviation of yearly arithmetic stock returns, bond returns, the short-term interest rate, and inflation, over the period June 1985 to March 2002. These are computed from the yearly arithmetic overlapping monthly returns. For comparison we show in the second column yearly Danish returns based on the long period 1900-2000 as reported in Dimson et al. (2002). As seen, stock returns are on average higher but also more variable than bond returns, which again are higher and more variable than short-term interest rates. Over the 1985-2002 period stocks have given a premium of a little less than $2 \%$ over bonds and approximately $5 \%$ over the risk-free rate. By comparing the two columns we see that the mean real stock return of $9.5 \%$ for the 1985-2002 period is much higher than the $6.2 \%$ reported by Dimson et al. for the longer period 1900-2000. Similarly, real bond returns have been much higher, and real interest rates somewhat higher, in the 1985-2002 period compared to the earlier period.

Table 4 reports the covariance/correlation matrix of the Danish yearly returns. Probably the most interesting aspect of this table is the positive correlation of approximately 0.25 between stocks and bonds. For the period 1922-1996, Engsted and Tanggaard (2001) report a correlation of 0.48 , so the Danish stock and bond markets have become less correlated lately. The positive correlation between stock and bond returns is quite interesting since it implies a negative correlation between stock returns and the long-term interest rate. This runs counter to what many practitioners believe to be the case: in the financial press practitioners often argue that when times are bad for the stock market investors fly into bonds, whereby interest rates decrease. This is probably true in the very short run (over a day or week), but Table 4 shows that over the longer 1-year horizon, when times are bad for the stock market typically they are also bad for the bond market. ${ }^{5}$

\footnotetext{
${ }^{5}$ Beltratti and Shiller (1992) and Campbell and Ammer (1993) also report positive correlations between stock and bond returns in the US. In a recent paper, Stivers and Sun (2002) show that the relationship between stock and bond returns is highly dependent on the volatility of the stock market. In times with low or normal volatility, stock and bond returns are positively correlated. However, during periods with high volatility, stock and bond returns are uncorrelated, or even negatively correlated.
} 


\subsection{Hansen-Jagannathan bound.}

The means, standard deviations and correlations reported in Tables 3 and 4 can be used to infer some key properties of the unknown stochastic discount factor that has generated the observed returns. It is well-known that the principle of no arbitrage implies that $E(m \mathbf{r})=1$, where $\mathbf{r}$ is the vector of gross returns and $m$ is the stochastic discount factor, see e.g. Campbell et al. (1997) and Cochrane (2001). That is, there exists a stochastic discount factor that correctly prices the assets. An interesting question is what economic model generates $m$. In the empirical finance literature it has proven to be quite difficult to explain the behaviour over time in asset returns using standard economic models from finance. The equity premium puzzle is an example of this. ${ }^{6}$ Hansen and Jagannathan (1991) have suggested a very popular method of inferring the properties of $m$ from the observed asset market data only, i.e. without setting up a particular economic model for $m$. They derive a lower bound for the standard deviation of $m, \sigma_{m}$, given the mean of $m, E m$, the mean of the vector of gross returns, Er , and the covariance matrix of returns, $\Omega$, (i is a vector of one's):

$$
\sigma_{m} \geqslant\left[(\mathbf{i}-E m E \mathbf{r})^{\prime} \Omega^{-1}(\mathbf{i}-E m E \mathbf{r})\right]^{\frac{1}{2}}
$$

On yearly US data $\sigma_{m}$ is found to be substantial, i.e. more than $30 \%$ (see e.g. Campbell et al., 1997). Plausible economic models for $m$, however, typically cannot generate so high volatility. For Denmark using yearly data over the period 1922-1996, Engsted (2002) finds that the minimum $\sigma_{m}$ is slightly lower than $20 \%$.

Figure 6 shows the Hansen-Jagannathan lower volatility bound computed as in (8) using the yearly Danish returns computed on the monthly data from June 1985 to March 2002. The minimum volatility of the stochastic discount factor is reached for $E m$ equal to 0.955 where $\sigma_{m}=$ $38 \%$. Thus, in recent years Danish asset returns have begun to behave more like US returns. An interesting question is whether the returns for the period since 1985 can be explained in terms of a simple consumption based asset pricing model. However, we leave that for future research. In the rest of the paper we analyze in more detail the statistical properties of Danish daily, weekly and monthly returns.

\footnotetext{
${ }^{6}$ The equity premium puzzle builds on the consumption-capital asset pricing model in which $m$ is a function of the intertemporal marginal rate of substitution in consumption.
} 


\subsection{Properties of daily and weekly stock returns.}

In Table 5 we report autocorrelations, Lagrange multiplier tests for autoregressive conditional heteroscedasticity (ARCH), c.f. Engle (1982), and Jarque and Bera (1980) tests for normality in daily and weekly log stock returns. Danish daily returns have a highly significant positive first-order autocorrelation (similar to what Campbell et al. (1997, Table 2.4) report for daily US stock returns), and they are highly heteroscedastic and non-normal. Weekly returns are also heteroscedastic and nonnormal, but here there is much less evidence for autocorrelation (similar to what Campbell et al. (1997) report for weekly value-weighted US stock returns).

\subsection{Properties of monthly returns.}

Table 6 reports skewness, kurtosis, and Jarque-Bera normality tests for monthly log stock returns, and now we also examine bond returns. As seen, the hypothesis that monthly log returns are normally distributed cannot be rejected at quite high significance levels. Table 7 shows autocorrelations and tests for ARCH. Monthly stock returns appear to be serially uncorrelated and homoscedastic. Thus, it seems that Danish monthly log stock returns are close to fulfilling the traditional capital market assumptions, i.e. serially uncorrelated, homoscedastic and normally distributed. ${ }^{7}$ Bond returns, on the contrary, have a highly significant positive fourth-order autocorrelation, and excess bond returns exhibit strong heteroscedasticity (nominal and real bond returns are less heteroscedastic).

\subsubsection{Variance ratio's for multi-period returns}

In recent years finance researchers have documented some quite interesting differences between short-term and long-term asset returns. In particular, stock returns in the US seem to display long-term meanreversion, that is, multi-year returns are negatively autocorrelated: from week to week, or month to month, returns are close to unpredictable, but periods where 3-, 4- or 5-year returns are high (low) tend to be followed by periods with low (high) multi-year returns. Poterba and Summers (1988) and Fama and French (1988a) were the first to document this phenomenon on US data. One way to examine this is to compute the variance ratio

\footnotetext{
${ }^{7}$ In the traditional mean-variance portfolio analysis of Markowitz (1952), and its extension in the form of CAPM (Sharpe, 1964; Lintner, 1965), returns must be normally, identically and independently distributed (unless investors have quadratic utility). It is well-known, however, that in general asset returns may be non-normal, serially correlated and heteroscedastic in an efficient market (see e.g. Leroy, 1989).
} 


$$
\operatorname{VR}(k)=\frac{\operatorname{var}\left(r_{t, t+k}\right)}{k \operatorname{var}\left(r_{t, t+1}\right)}=1+2 \sum_{j=1}^{k-1}\left(1-\frac{j}{k}\right) \rho_{j}
$$

where $\operatorname{var}\left(r_{t, t+k}\right)$ is the variance of the $k$-period log return, and $\rho_{j}$ is the $j$ 'th order autocorrelation. If returns are truly independent over time, $\operatorname{var}\left(r_{t, t+k}\right)$ will equal $k \operatorname{var}\left(r_{t, t+1}\right)$, so VR will equal one. If returns are negatively correlated (mean-reversion), VR will be less than one. If returns are positively correlated (mean-aversion), VR will be larger than one. Lo and MacKinlay (1988) derive the limiting distribution of $\widehat{\mathrm{VR}}(k)$ under the null that $\mathrm{VR}=1$, and they derive a heteroscedasticityconsistent estimate of its variance.

Table 8 reports variance ratio's for the Danish stock and bond returns measured over horizons from 3 months to 48 months (4 years). For real and excess stock returns, VR is in all cases larger than or equal to one, meaning that stock returns exhibit mean-aversion. The strongest meanaversion occurs at a 12-month horizon, where VR is significantly larger than one at a $5 \%$ level for excess returns and at a $10 \%$ level for real returns. For all other horizons, however, VR is not significantly different from one. Thus, it seems that Danish stock returns do not display the long-horizon mean-reversion property that many authors have found to characterize US stock returns. If anything, Danish stock returns are mean-averting. Bond returns also show mean-aversion at horizons up to 12 months, but at longer horizons bond returns are mean-reverting. Note, however, that in no case for bonds is VR significantly different from one.

\subsubsection{Predictability of multi-period returns}

An alternative way to test for long-term mean-reversion is to regress the $k$-period return onto itself lagged $k$ periods:

$$
r_{t, t+k}=\alpha+\beta r_{t-k, t}+\varepsilon_{t+k}
$$

$\beta$ less than one implies mean-reversion, while $\beta$ larger than one implies mean-aversion. Table 9 reports $R^{2}$ values and estimates of $\beta$ and their standard errors from regression (10). Due to the presence of timeoverlapping returns when $k>1$, the error term in (10) exhibits moving average of order $k-1$, so $s e(\widehat{\beta})$ is estimated using the Newey and West (1987) correction. $\beta$-estimates are significantly larger than one for $k=3$ months and insignificantly less than one for $k$ between 12 and 36 months. With a 4 -year horizon $\widehat{\beta}$ is less than -0.5 and marginally significant at a $5 \%$ level for real returns. These results are somewhat different from the results based on the variance ratio's, and indicate that long-term Danish 
stock returns may exhibit mean-reversion. In principle, tests for meanreversion based on (9) and (10) should give the same result. However, in finite samples the two procedures may give quite different results, especially when $k$ is large. This is because in (10) the effective number of observations is $k$ smaller than in (9). This may explain why the results in Tables 8 and 9 are qualitatively different for some $k$ values. Cochrane (2001, section 20.1) reports the same phenomenon on US data. ${ }^{8}$

In Table 9 we also report tests for predictability of stock returns based on the dividend-price ratio:

$$
r_{t, t+k}=\alpha+\beta(d-p)_{t}+\varepsilon_{t+k}
$$

$(d-p)_{t}$ is the log dividend-price ratio. Beginning with Fama and French (1988b), several authors have documented that in the US a low (high) dividend-price ratio signals lower (higher) future multi-year stock returns. $^{9}$ Table 9 shows that for horizons up to 3 years, a low (high) Danish dividend-price ratio signals lower (higher) future stock returns. However, the evidence is quite weak: all $R^{2}$-values are very close to zero, and only for $k=24$ months is the predictability (marginally) statistically significant. At the 4 -year horizon the $\beta$-estimates are negative but highly insignificant.

\section{Concluding remarks}

In this paper we have constructed a new daily market index that includes dividends, for the Danish stock market covering the period from June 1985 to March 2002, and we have used this new index to analyze the time-series properties and predictability of stock returns at various frequencies and horizons.

Daily returns are highly autocorrelated, heteroscedastic and nonnormal. Weekly returns are also heteroscedastic and non-normal, but appear to be serially uncorrelated. Monthly stock returns are found to be serially uncorrelated, homoscedastic and normally distributed. Variance ratio tests indicate that Danish stock returns are not mean-reverting,

\footnotetext{
${ }^{8}$ In general, for large $k$ the finite-sample properties of tests based on (9) and (10) may be quite different from the asymptotic properties, see e.g. Richardson and Stock (1989) and Kirby (1997). This means that care should be taken when interpreting the outcome of such tests.

${ }^{9}$ One may speculate whether return predictability based on the dividend-price ratio is just another way of measuring mean-reversion. This may be the case, but not necessarily: Cochrane (2001, ch.20) shows that predictability based on $d$ - $p$ may or may not imply mean-reversion (he argues that long-horizon US stock returns are strongly predictable from $d-p$ but at the same time do not display strong meanreversion).
} 
not even at long horizons. If anything, stock returns appear to be meanaverting. However, based on multi-period autoregressions there is some evidence of long-horizon mean-reversion. The dividend-price ratio shows no strong ability to predict short- or long-horizon stock returns. Finally, we find that, using the Hansen-Jagannathan methodology, the underlying stochastic discount factor generating Danish asset returns is quite volatile.

Hopefully, the new stock price index presented in this paper will serve the basis for further analyses of the Danish stock market, e.g. tests of specific asset pricing models, and for portfolio evaluation exercises where the new index may be used as a benchmark.

\section{References.}

Allen, R. G. D. (1975): Index Numbers in Theory and Practice. Aldine Publishing Company.

Campbell, J.Y. (1999): Asset prices, consumption, and the business cycle. In: Taylor, J.B. and M. Woodford (eds.), Handbook of Macroeconomics. North-Holland, Amsterdam.

Campbell, J.Y., and J. Ammer (1993): What moves the stock and bond markets? A variance decomposition for long term asset returns. Journal of Finance 48, 3-37.

Campbell, J.Y., A.W. Lo, and A.C. MacKinlay (1997): The Econometrics of Financial Markets. Princeton University Press.

Cochrane, J.H. (2001): Asset Pricing. Princeton University Press.

Dimson, E., and P. Marsh (2001): U.K. financial market returns. Journal of Business 74, 1-31.

Dimson, E., P. Marsh, and M. Staunton (2002): Triumph of the Optimists. 101 Years of Global Investment Returns. Princeton University Press.

Engle, R.F. (1982): Autoregressive conditional heteroscedasticity with estimates of the variance of UK inflation. Econometrica 50, 9871008 .

Engsted, T. (2002): Measures of fit for rational expectations models. Journal of Economic Surveys 16, 301-356.

Engsted, T., and C. Tanggaard (1999): Risikopræmien på danske aktier. Nationaløkonomisk Tidsskrift 137, 164-177.

Engsted T., and C. Tanggaard (2001): The Danish stock and bond markets: Comovement, return predictability and variance decomposition. Journal of Empirical Finance 8, 243-271.

Engsted, T., E. Mammen, and C. Tanggaard (2000): Evaluating the C-CAPM and the equity premium puzzle at short and long horizons: A Markovian bootstrap approach. Working Paper, Aarhus School of 
Business.

Fama, E., and K. French (1988a): Permanent and temporary components of stock prices: Journal of Political Economy 96, 246-273.

Fama, E., and K. French (1988b): Dividend yields and expected stock returns. Journal of Financial Economics 22, 3-27.

Fisher, L., and D. G. Weaver (1992): Dealing with short-term anomalies in the relative prices of securities. Working paper, Rutgers University, 1992.

Frennberg, P., and B. Hansson (1992): Computation of a monthly index for Swedish stock returns 1919-1989. Scandinavian Economic History Review 40, 3-7.

Hansen, L.P., and R. Jagannathan (1991): Implications of security market data for models of dynamic economies. Journal of Political Economy 99, 225-264.

Jarque, C.M., and A.K. Bera (1980): Efficient tests for normality, homoscedasticity and serial dependence of regression residuals. Economics Letters 6, 255-259.

Jorion, P. and W.N. Goetzmann (1999): Global stock markets in the Twentieth Century. Journal of Finance 54, 953-980.

Kirby, C. (1997): Measuring the predictable variation in stock and bond returns. Review of Financial Studies 10, 579-630.

LeRoy, S.F. (1989): Efficient capital markets and martingales. Journal of Economic Literature 27, 1583-1621.

Lintner, J. (1965): The valuation of risky assets and the selection of risky investments in stock portfolios and capital budgets. Review of Economics and Statistics 47, 13-37.

Lo, A.W., and A.C. MacKinlay (1988): Stock prices do not follow random walks: Evidence from a simple specification test. Review of Financial Studies 1, 41-66.

Lund, J. (1992): Rationelle bobler i de danske aktiekurser 1923-1991 - en empirisk analyse. Nationaløkonomisk Tidsskrift 130, 483-497.

Lund J., and T. Engsted (1996): GMM and present value tests of the C-CAPM: Evidence from the Danish, German, Swedish and UK stock markets. Journal of International Money and Finance 15, 497-521.

Markowitz, H. (1952): Portfolio selection. Journal of Finance 7, 77-99.

Mehra, R., and E. Prescott (1985): The equity premium: A puzzle? Journal of Monetary Economics 15, 145-161.

Newey, W.K., and K.D. West (1987): A simple, positive sime-definite, heteroscedasticity and autocorrelation consistent covariance matrix. Econometrica 55, 703-708.

NOREX (2000): Rules for the construction and maintenance of the 
NOREX exchanges' all-share, sector and benchmark indices. Version 1.0 .

Parum, C. (1999): Historisk afkast af aktier og obligationer i Danmark. Finans/Invest, 4-13.

Poterba, J., and L.H. Summers (1988): Mean reversion in stock returns: Evidence and implications. Journal of Financial Economics 22, 27-60.

Shiller, R.J., and A.E. Beltratti (1992): Stock prices and bond yields: Can their comovement be explained in terms of present value models. Journal of Monetary Economics 30, 25-46.

Richardson, M., and J.H. Stock (1989): Drawing inferences from statistics based on multi-year asset returns. Journal of Financial Economics 25, 323-348.

Sharpe, W. (1964): Capital asset prices: A theory of market equilibrium under conditions of risk. Journal of Finance 19, 425-442.

Stivers, C. and L. Sun (2002): Stock market uncertainty and the relation between stock and bond returns. Federal Reserve Bank of Atlanta WP 2002-3. 


\begin{tabular}{|l|lll|}
\hline Frequency & Daily & Monthly & Quarterly \\
\hline Corr $(\Delta$ price index $(\mathrm{t}), \Delta \mathrm{KFX}(\mathrm{t}))$ & 0.842 & 0.991 & 0.996 \\
Number of observations & 3064 & 146 & 48 \\
\hline
\end{tabular}

Table 1: Correlation between the official KFX index and our price index, July 1989 - March 2002. Note: The table reports correlation coefficients between the change in the official KFX index and the change in the new price index at varying frequencies. 


\begin{tabular}{|c|c|c|}
\hline Algorithm & $w_{i}$ & Link-relative \\
\hline Value weighted & $n_{i}(t-j) p_{i}(t-j)$ & $\sum_{i=1}^{N} n_{i} p_{i}(t) / \sum_{i=1}^{N} n_{i} p_{i}(t-j)$ \\
\hline Price weighted & $p_{i}(t-j)$ & $\sum_{i=1}^{N} p_{i}(t) / \sum_{i=1}^{N} p_{i}(t-j)$ \\
\hline Equal weighted & 1 & $1 / N\left[\sum_{i=1}^{N} p_{i}(t) / p_{i}(t-j)\right]$ \\
\hline
\end{tabular}

Table 2: Specification of the link-relative. Note: The table specifies the link-relative (chaining formula) in each of three special cases: the market value weighted, the price weighted and the equally weighted index. $N$ is the number of stocks in the index portfolio, subscript $i$ refers to the $i$ th stock, and $t$ is an index of the actual trading data. The other variables are: $n_{i}(t)$, the number of outstanding shares for the $i t h$ stock, and $p_{i}(t)$, the share price. 


\begin{tabular}{|c|c|c|}
\hline & $\begin{array}{c}\text { 1985-2002 (our data) } \\
\text { mean (std.dev) }\end{array}$ & $\begin{array}{c}\text { 1900-2000 (Dimson et al.) } \\
\text { mean (std.dev) }\end{array}$ \\
\hline Nominal stocks & $12.5(24.5)$ & $10.7(21.7)$ \\
\hline bonds & $10.6(8.4)$ & $7.3(11.0)$ \\
\hline risk-free & $7.3(3.1)$ & $7.1(4.5)$ \\
\hline inflation & $2.7(1.1)$ & $4.3(6.5)$ \\
\hline stocks & $9.5(23.7)$ & $6.2(20.1)$ \\
\hline bonds & $7.8(8.3)$ & $3.3(12.5)$ \\
\hline risk-free & $4.4 \quad(2.9)$ & $3.0(6.4)$ \\
\hline
\end{tabular}

Table 3: Yearly arithmetic returns. Note: The numbers in the first column are based on yearly arithmetic overlapping returns computed on monthly data from June 1985 to March 2002. The numbers in the second column are from Table 21-1 in Dimson et al. (2002). 


\begin{tabular}{|rr|cccc|}
\hline & & stocks & bonds & risk-free & inflation \\
\hline Nominal & stocks & 0.0581 & 0.0052 & -0.0023 & 0.0004 \\
& bonds & 0.256 & 0.0070 & 0.00006 & -0.00006 \\
& risk-free & -0.306 & 0.024 & 0.0010 & 0.00009 \\
& inflation & 0.157 & -0.064 & 0.265 & 0.0001 \\
& & & & & \\
\multirow{4}{*}{ Real } & stocks & 0.0562 & 0.0048 & -0.0026 & \\
& bonds & 0.242 & 0.0069 & 0.00015 & \\
& risk-free & -0.371 & 0.060 & 0.00087 & \\
\hline
\end{tabular}

Table 4: Covariance/correlation matrix of yearly arithmetic returns. Note: The numbers in the diagonal are variances; the numbers above the diagonal are covariances; the numbers below the diagonal are correlations. Based on yearly arithmetic overlapping returns from June 1985 to March 2002. 


\begin{tabular}{|c|c|c|c|c|c|c|c|c|c|}
\hline & & $\operatorname{lag}=1$ & 2 & 3 & 4 & 5 & 6 & 7 & 8 \\
\hline \multirow{2}{*}{ Daily returns } & $\mathrm{ACF}$ & $0.126^{* *}$ & -0.020 & -0.002 & 0.014 & 0.001 & $-0.027^{*}$ & 0.005 & 0.014 \\
\hline & $\mathrm{ARCH}$ & $361.9^{* *}$ & $361.9^{* *}$ & $370.4^{* *}$ & $384.7^{* *}$ & $386.9^{* *}$ & $386.9^{* *}$ & $398.6^{* *}$ & $399.5^{* *}$ \\
\hline \multicolumn{10}{|c|}{ Jarque-Bera $=11634^{* *}$} \\
\hline \multirow[t]{2}{*}{ Weekly returns } & $\mathrm{ACF}$ & -0.008 & 0.028 & 0.050 & $-0.062^{*}$ & $0.065^{*}$ & 0.014 & -0.040 & -0.005 \\
\hline & $\mathrm{ARCH}$ & 2.97 & 3.08 & 4.00 & 6.49 & $18.36^{* *}$ & $20.80^{* *}$ & $22.89^{* *}$ & $22.89^{* *}$ \\
\hline \multicolumn{2}{|c|}{ Jarque-Bera $=411.2^{* *}$} & & & & & & & & \\
\hline
\end{tabular}

Table 5: Autocorrelations and tests for ARCH and normality in daily and weekly log stock returns. Note: $\mathrm{ACF}$ denotes autocorrelations. ARCH is a Lagrange multiplier test for autoregressive conditional heteroscedasticity, distributed as $\chi^{2}$ with degrees of freedom equal to the number of lags. Jarque-Bera is a $\chi^{2}(2)$ test for normality (Jarque and Bera, 1980). * and ${ }^{* *}$ denote significance at a $10 \%$ and $5 \%$ level, respectively. Based on daily and weekly log stock returns from June 1985 to March 2002 


\begin{tabular}{|c|ccc|}
\hline & Skewness & Kurtosis & Jarque-Bera \\
\hline Nominal stocks returns & -0.192 & 0.234 & 1.677 \\
& $(0.272)$ & $(0.507)$ & $(0.432)$ \\
& & & \\
Real stock returns & -0.186 & 0.213 & 1.524 \\
& $(0.286)$ & $(0.546)$ & $(0.467)$ \\
Excess stock returns & -0.181 & 0.197 & 1.408 \\
& $(0.301)$ & $(0.577)$ & $(0.495)$ \\
& & & \\
Nominal bond returns & -0.191 & 0.229 & 1.595 \\
& $(0.281)$ & $(0.523)$ & $(0.450)$ \\
& & & \\
Real bond returns & -0.169 & 0.136 & 1.067 \\
& $(0.342)$ & $(0.705)$ & $(0.587)$ \\
Excess bond returns & -0.319 & 0.232 & 3.706 \\
& $(0.072)$ & $(0.517)$ & $(0.157)$ \\
\hline
\end{tabular}

Table 6: Skewness, kurtosis, and tests for normality of monthly log returns. Note: The statistics are computed based on monthly log returns from June 1985 to March 2002. The numbers in parentheses are p-values in tests for normality. 


\begin{tabular}{|c|c|c|c|c|c|c|c|c|c|}
\hline & & $\operatorname{lag}=1$ & 2 & 3 & 4 & 5 & 6 & 7 & 8 \\
\hline \multicolumn{2}{|c|}{ Nominal stocks $\mathrm{ACF}$} & 0.04 & 0.03 & 0.06 & 0.08 & 0.12 & 0.07 & -0.07 & 0.01 \\
\hline \multicolumn{2}{|c|}{$\mathrm{ARCH}$} & 0.00 & 1.28 & 2.79 & 3.20 & 3.27 & 4.88 & 6.50 & 6.48 \\
\hline \multirow[t]{2}{*}{ Real stocks } & $\mathrm{ACF}$ & 0.05 & 0.01 & 0.05 & 0.07 & 0.12 & 0.08 & -0.0 & 0.00 \\
\hline & $\mathrm{ARCH}$ & 0.00 & 1.07 & 2.32 & 2.89 & 3.03 & 4.67 & 6.82 & 6.83 \\
\hline \multirow[t]{2}{*}{ Excess stocks } & $\mathrm{ACF}$ & 0.06 & 0.04 & 0.07 & 0.09 & 0.13 & 0.09 & -0.06 & 0.02 \\
\hline & $\mathrm{ARCH}$ & 0.20 & 0.74 & 1.56 & 1.84 & 1.85 & 3.11 & 4.30 & 4.28 \\
\hline \multirow[t]{2}{*}{ Nominal bonds } & $\mathrm{ACF}$ & 0.07 & 0.11 & -0.05 & $0.21^{* *}$ & -0.05 & 0.03 & 0.03 & 0.01 \\
\hline & $\mathrm{ARCH}$ & 0.45 & 1.12 & 4.09 & 4.58 & 6.51 & 7.25 & $12.89^{*}$ & $14.14^{*}$ \\
\hline \multirow[t]{2}{*}{ Real bonds } & $\mathrm{ACF}$ & 0.06 & 0.13 & -0.06 & $0.18^{* *}$ & -0.05 & 0.06 & 0.05 & -0.01 \\
\hline & $\mathrm{ARCH}$ & 0.58 & 2.28 & 4.31 & 4.74 & 6.06 & 7.14 & 11.37 & 11.94 \\
\hline \multirow[t]{2}{*}{ Excess bonds } & $\mathrm{ACF}$ & 0.06 & 0.10 & -0.06 & $0.21^{* *}$ & -0.05 & 0.03 & 0.03 & 0.02 \\
\hline & $\mathrm{ARCH}$ & 0.72 & $6.60^{* *}$ & $10.49^{* *}$ & $14.38^{* *}$ & $16.24^{* *}$ & $16.44^{* *}$ & $18.61^{* *}$ & $22.31^{* *}$ \\
\hline
\end{tabular}

Table 7: Autocorrelations and tests for ARCH in monthly log returns. Note: ACF denotes autocorrelations. $\mathrm{ARCH}$ is a Lagrange multiplier test for autoregressive conditional heteroscedasticity, distributed as $\chi^{2}$ with degrees of freedom equal to the number of lags. ${ }^{*}$ and ${ }^{* *}$ denote significance at a $10 \%$ and $5 \%$ level, respectively. Based on monthly log returns from June 1985 to March 2002. 


\begin{tabular}{|c|ccccc|}
\hline & $\mathrm{k}=3$ & 12 & 24 & 36 & 48 \\
\hline Real stock returns & 1.089 & 1.468 & 1.281 & 1.135 & 1.000 \\
& $(0.406)$ & $(0.082)$ & $(0.474)$ & $(0.779)$ & $(1.000)$ \\
& & & & & \\
Excess stock returns & 1.112 & 1.622 & 1.538 & 1.463 & 1.373 \\
& $(0.301)$ & $(0.021)$ & $(0.170)$ & $(0.335)$ & $(0.498)$ \\
& & & & & \\
Real bond returns & 1.160 & 1.465 & 0.917 & 0.756 & 0.687 \\
& $(0.183)$ & $(0.113)$ & $(0.842)$ & $(0.628)$ & $(0.584)$ \\
& & & & & \\
Excess bond returns & 1.145 & 1.463 & 0.958 & 0.757 & 0.652 \\
& $(0.234)$ & $(0.124)$ & $(0.921)$ & $(0.634)$ & $(0.547)$ \\
\hline
\end{tabular}

Table 8: Variance ratio's $(\mathbf{V R})$ and tests for $\mathbf{V R}=1$. Note: The numbers in parentheses are p-values in heteroscedasticity-consistent tests for whether VR equals one (c.f. Lo and MacKinlay, 1988). Based on monthly log returns from June 1985 to March 2002. 


\begin{tabular}{|c|c|c|c|c|}
\hline$r_{t, t+k}$ & $\begin{array}{r}\text { Real } \\
r_{t-k, t}\end{array}$ & $\begin{array}{l}\text { return } \\
(d-p)_{t}\end{array}$ & $\begin{array}{c}\text { Excess } \\
r_{t-k, t}\end{array}$ & $\begin{array}{l}\text { return } \\
(d-p)_{t}\end{array}$ \\
\hline$k=1$ & 0.049 & 0.001 & 0.057 & -0.000 \\
\hline $\operatorname{se}(\widehat{\beta})$ & $(0.071)$ & $(0.009)$ & $(0.073)$ & $(0.009)$ \\
\hline$R^{2}$ & 0.002 & 0.000 & 0.003 & 0.000 \\
\hline$k=3$ & 0.158 & 0.014 & 0.203 & 0.010 \\
\hline $\operatorname{se}(\widehat{\beta})$ & $(0.076)$ & $(0.025)$ & $(0.077)$ & $(0.025)$ \\
\hline$R^{2}$ & 0.025 & 0.004 & 0.041 & 0.002 \\
\hline$k=12$ & -0.173 & 0.142 & -0.081 & 0.131 \\
\hline $\operatorname{se}(\widehat{\beta})$ & $(0.158)$ & $(0.093)$ & $(0.151)$ & $(0.094)$ \\
\hline$R^{2}$ & 0.033 & 0.078 & 0.007 & 0.058 \\
\hline$k=24$ & -0.245 & 0.195 & -0.081 & 0.174 \\
\hline $\operatorname{se}(\widehat{\beta})$ & $(0.175)$ & $(0.082)$ & $(0.192)$ & $(0.091)$ \\
\hline$R^{2}$ & 0.075 & 0.104 & 0.008 & 0.062 \\
\hline$k=36 \quad \widehat{\beta}$ & -0.253 & 0.075 & -0.139 & 0.025 \\
\hline $\operatorname{se}(\widehat{\beta})$ & $(0.175)$ & $(0.136)$ & $(0.204)$ & $(0.160)$ \\
\hline$R^{2}$ & 0.067 & 0.012 & 0.018 & 0.001 \\
\hline$k=48$ & -0.619 & -0.085 & -0.552 & -0.171 \\
\hline $\operatorname{se}(\widehat{\beta})$ & $(0.303)$ & $(0.163)$ & $(0.358)$ & $(0.196)$ \\
\hline$R^{2}$ & 0.197 & 0.012 & 0.145 & 0.031 \\
\hline
\end{tabular}

Table 9: Regressions of multi-period stock returns onto lagged multi-period stock returns and the dividend-price ratio. Note: $r_{t, t+k}$ denotes the log return from $t$ to $t+k .(d-p)_{t}$ is the log dividendprice ratio. $s e(\widehat{\beta})$ denotes Newey and West (1987) standard errors. Based on monthly stock returns from June 1985 to March 2002. 


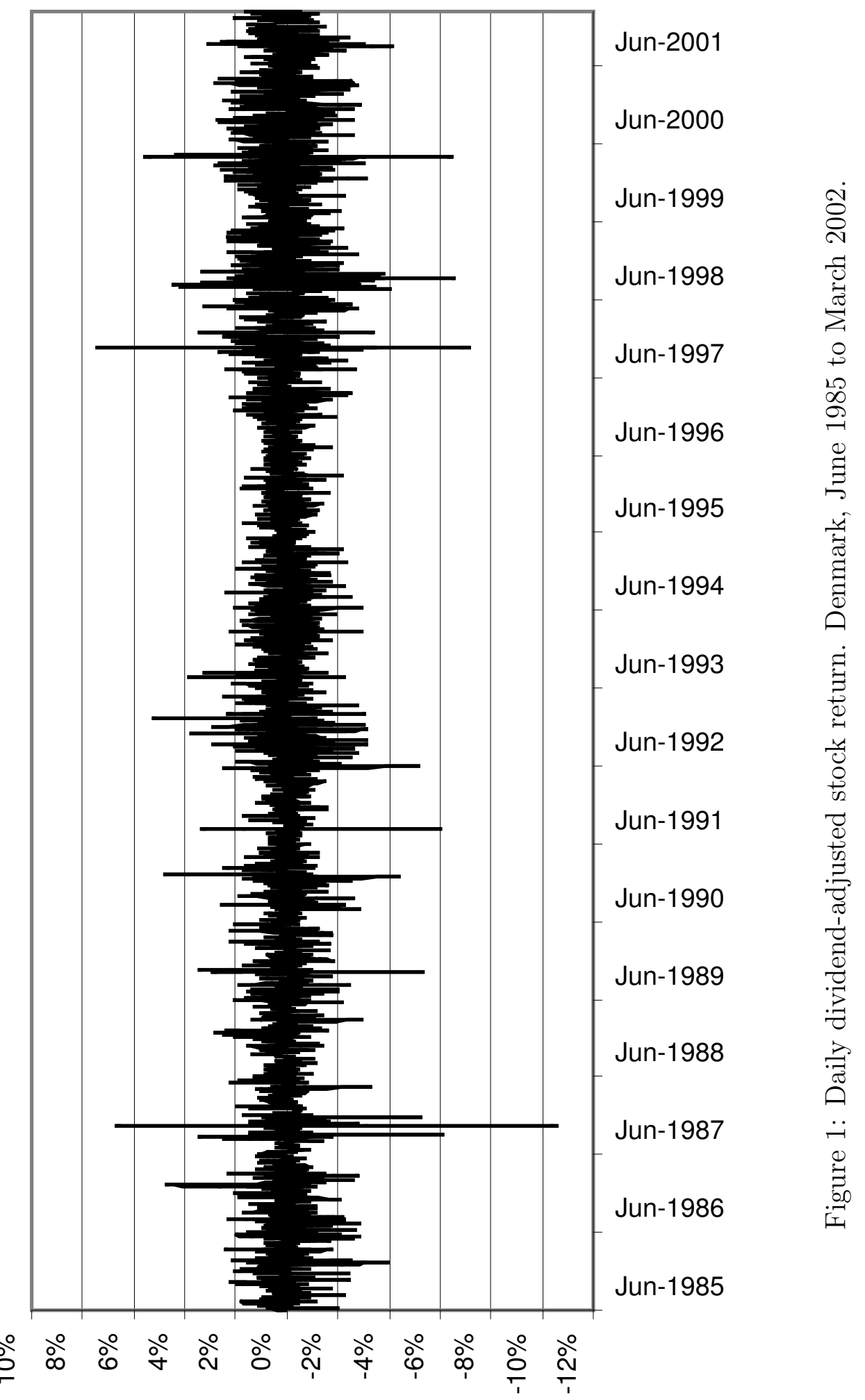




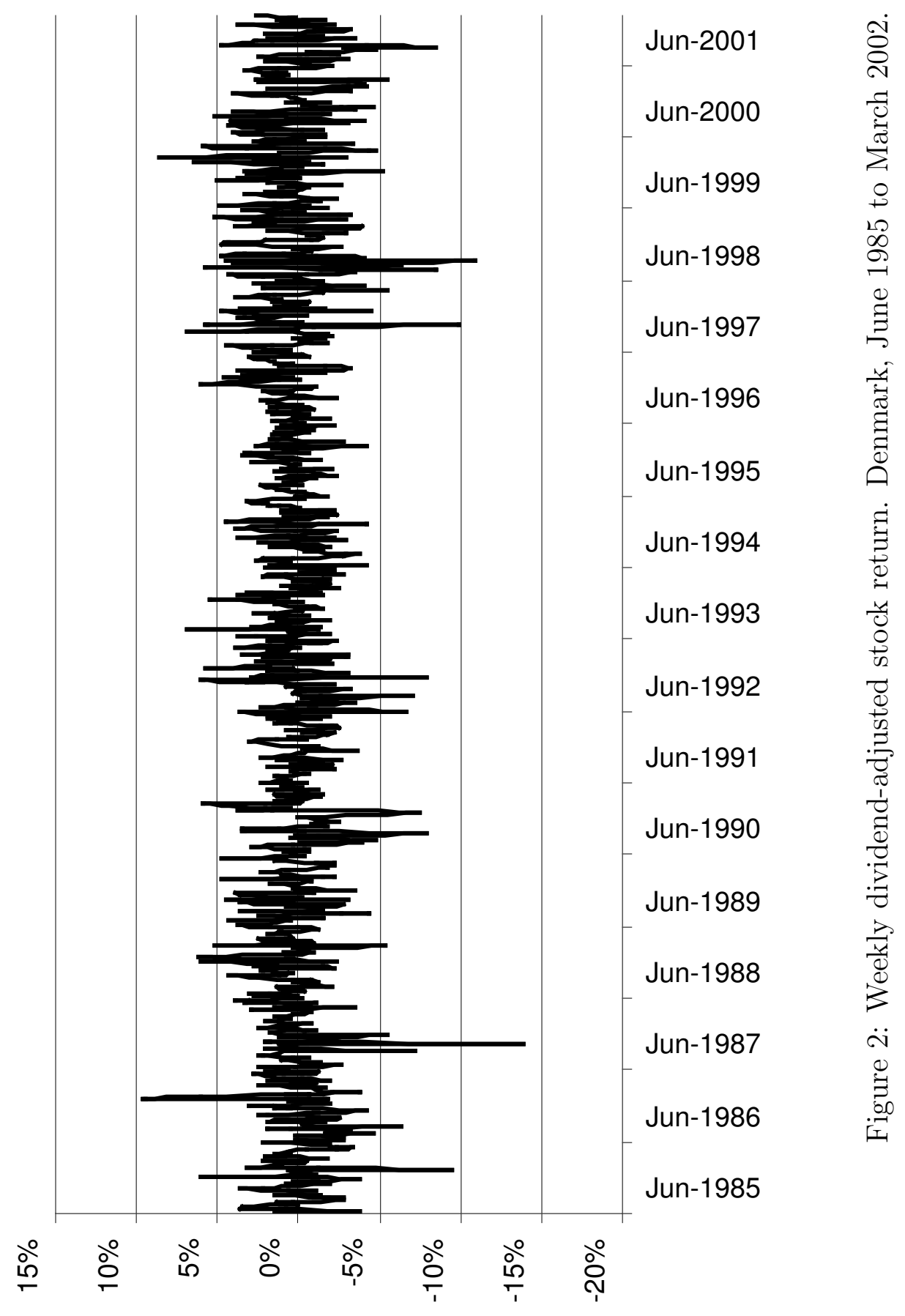




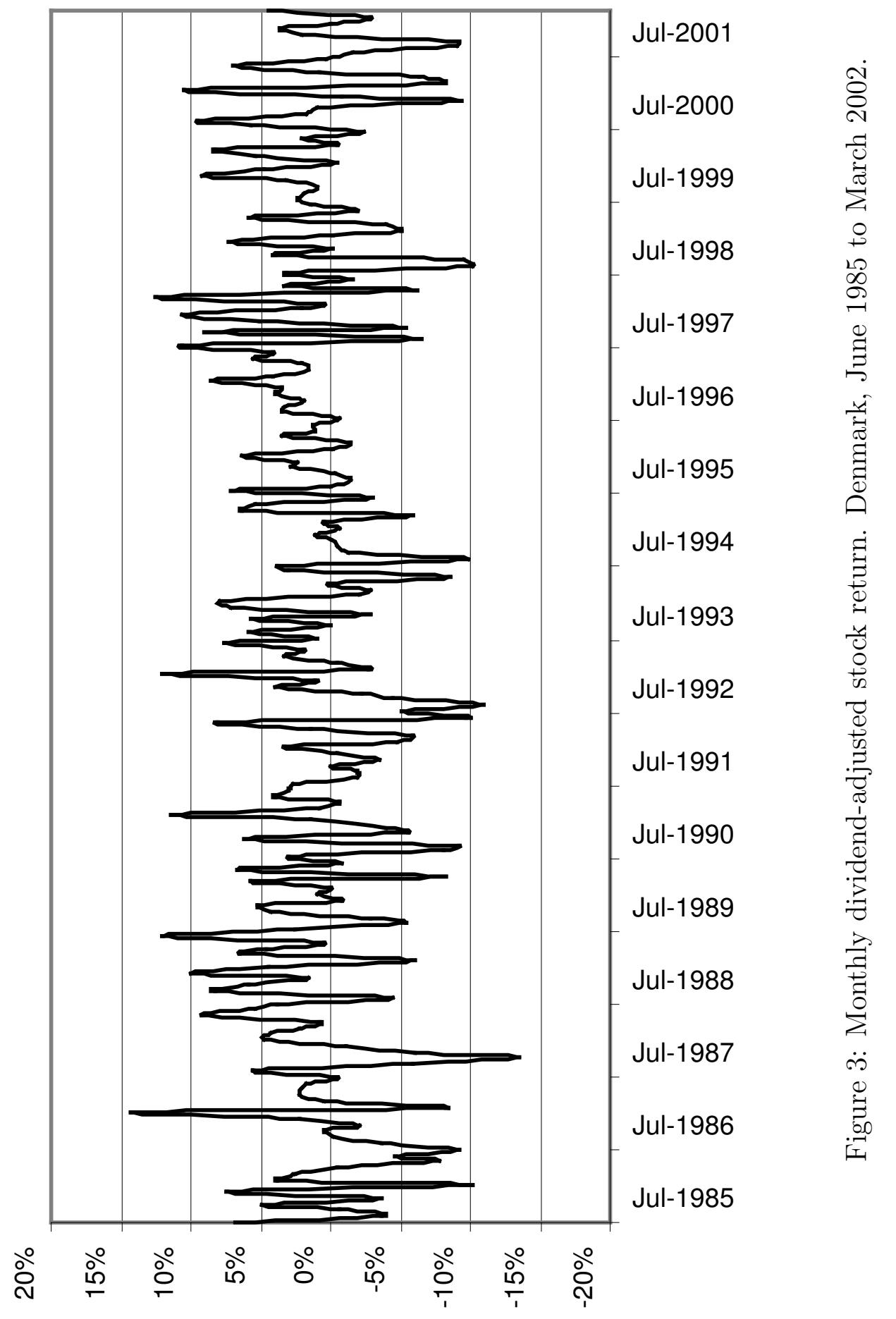




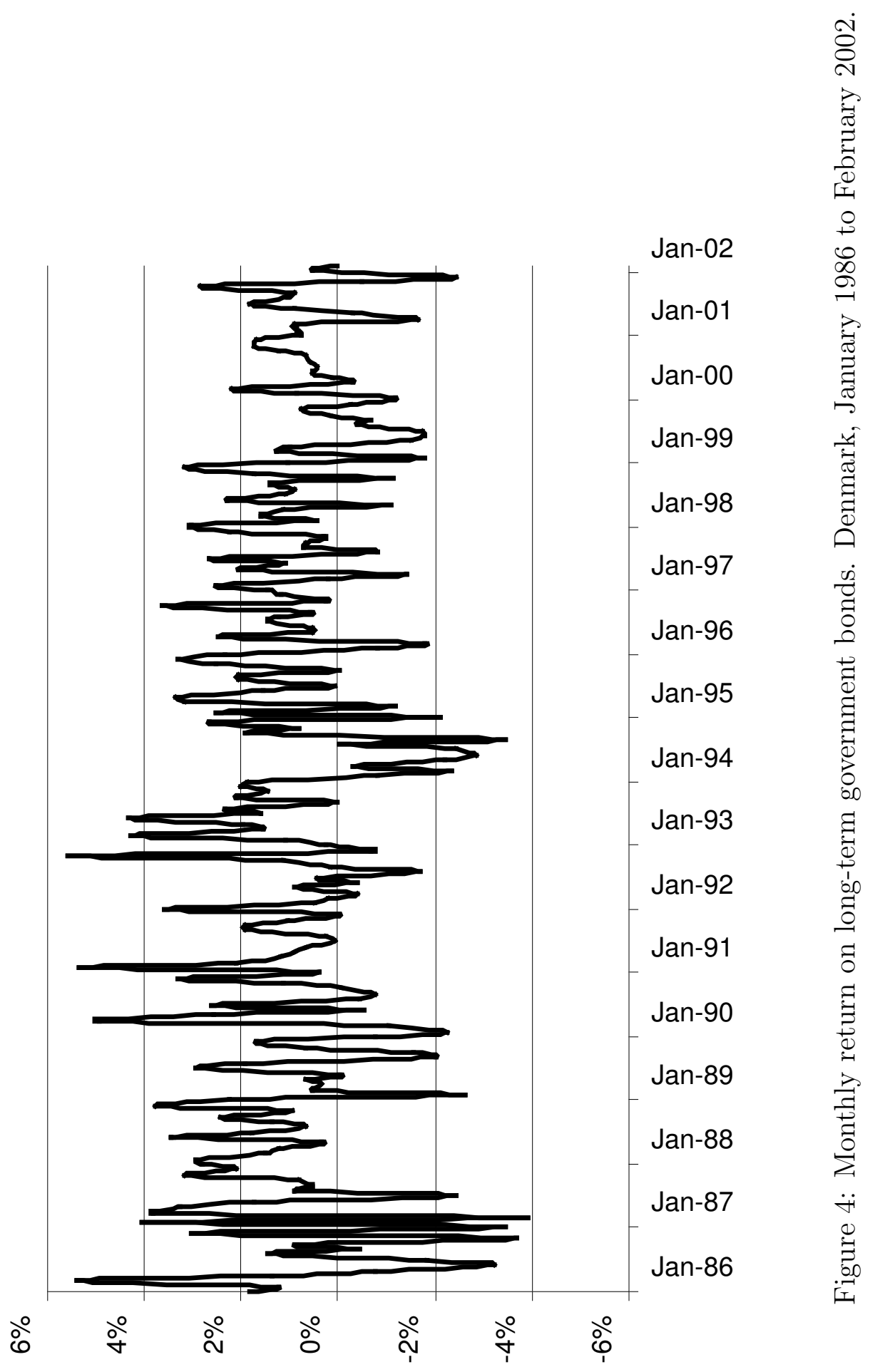

29 


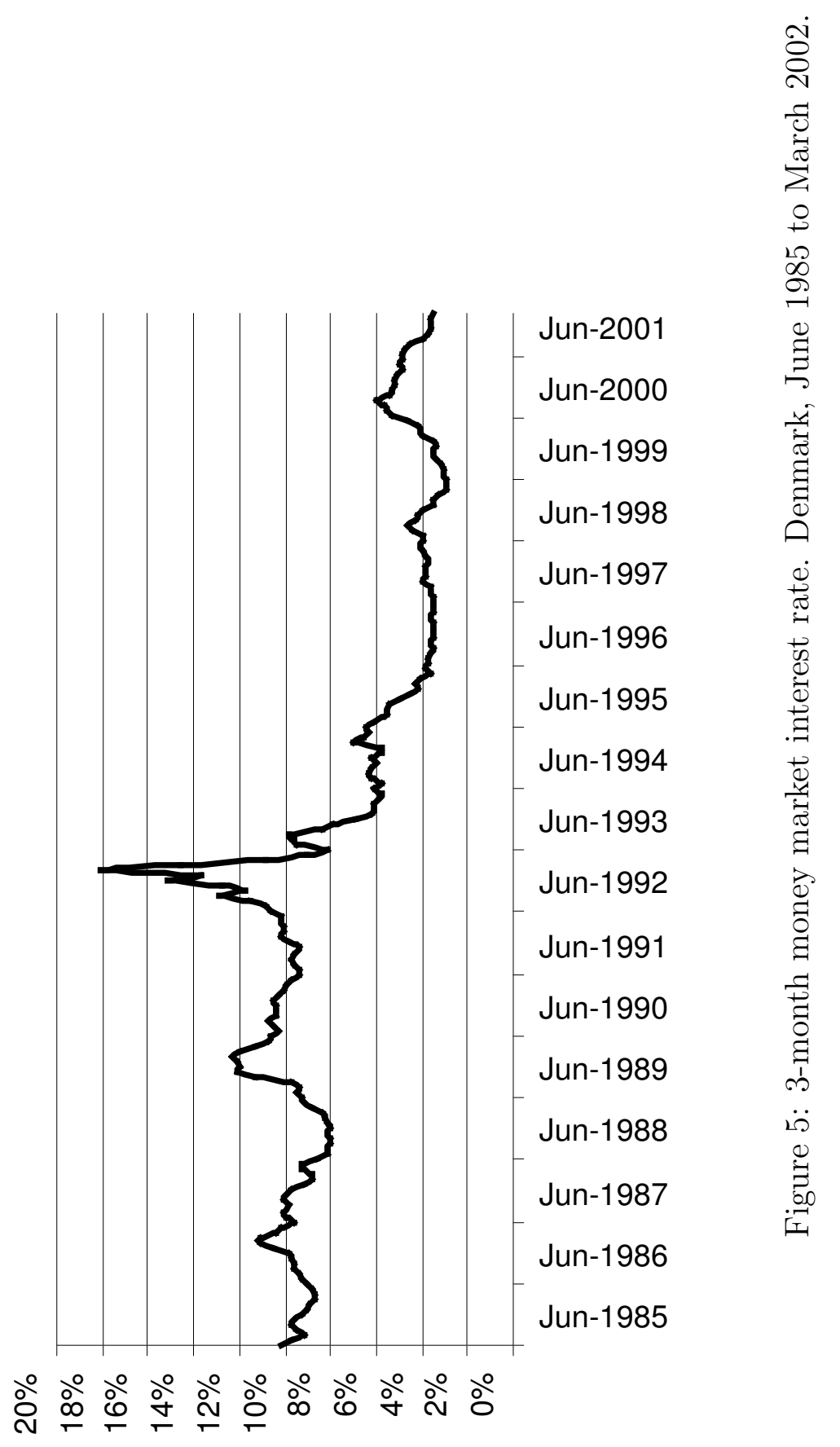




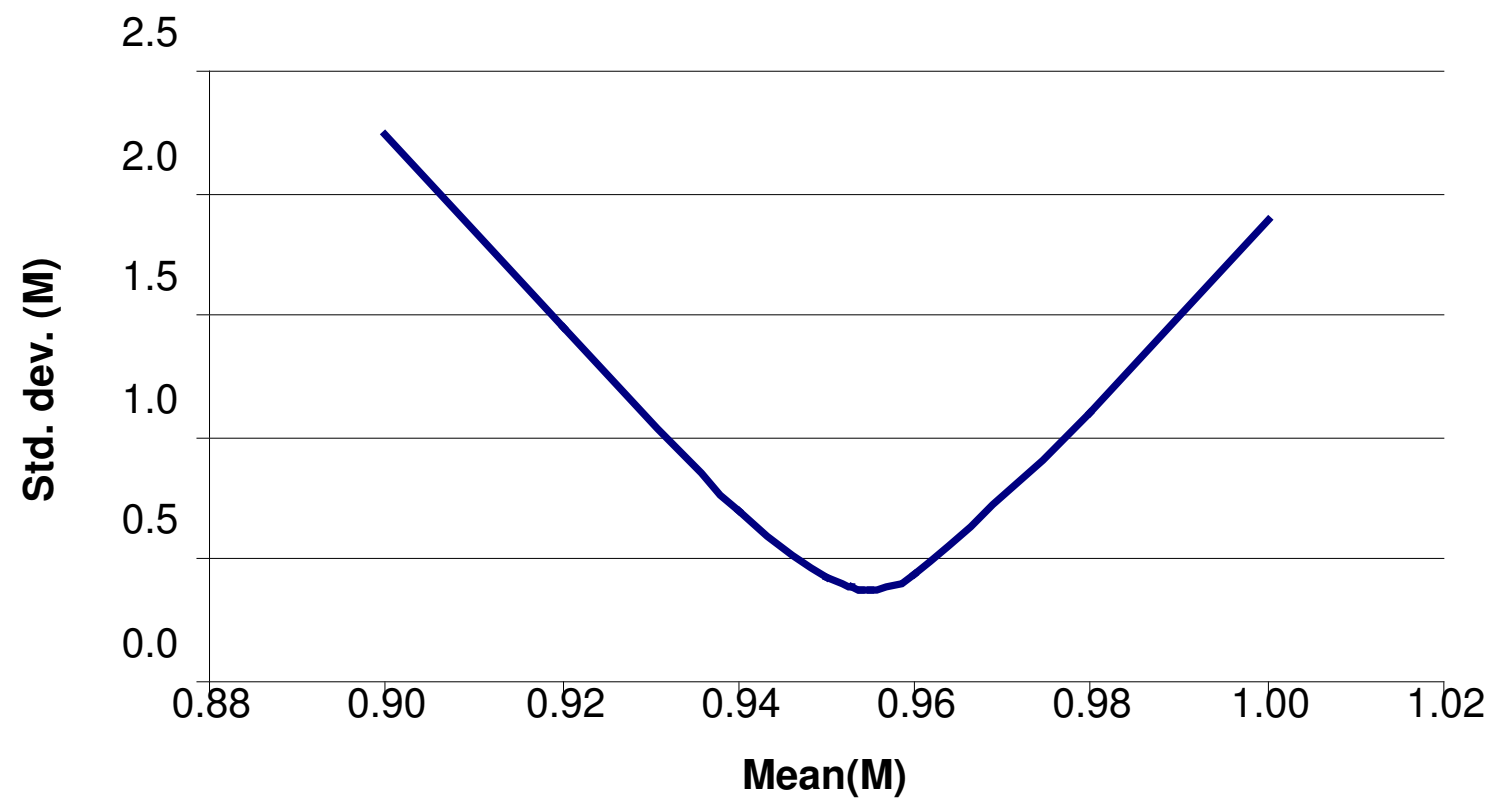

Figure 6: 3-month money market interest rate. Denmark, June 1985 to March 2002. 